\title{
Dectin-1 expression by macrophages and related antifungal mechanisms in a murine model of Sporothrix schenckii sensu stricto systemic infection
}

\author{
Juliana Aparecida Jellmayer, Lucas Souza Ferreira, Francine Alessandra Manente, \\ Amanda Costa Gonçalves, Marisa Campos Polesi, Alexander Batista-Duharte, \\ Iracilda Zeppone Carlos*
}

Department of Clinical Analysis, Faculty of Pharmaceutical Sciences of Araraquara, São Paulo State University “Júlio de Mesquita Filho " - UNESP,

Araraquara, SP, Brazil

\section{A R T I C L E I N F O}

\section{Article history:}

Received 2 December 2016

Received in revised form

28 April 2017

Accepted 19 June 2017

Available online 20 June 2017

\section{Keywords:}

$\beta$-1,3-Glucan

Dectin-1

Macrophage activation

Nitric oxide

Cytokines

Sporothrix schenckii

\begin{abstract}
A B S T R A C T
The available information about the role of Dectin- 1 in sporotrichosis is scarce. Hence, we aimed to assess Dectin-1 expression by macrophages and the activation of some related antifungal mechanisms during the Sporothrix schenckii sensu stricto infection as a first attempt to elucidate the role of this receptor in sporotrichosis. Balb/c mice were intraperitoneally infected with S. schenckii sensu stricto yeast ATCC 16345 and euthanized on days 5, 10 and 15 post-infection, when the following parameters were evaluated: fungal burden in spleen, Dectin-1 expression and nitric oxide (NO) production by peritoneal macrophages, as well as IL-1 $\beta$, TNF- $\alpha$ and IL-10 ex vivo secretion by these same cells. Peritoneal macrophages were ex vivo challenged with either the alkali-insoluble fraction (F1) extracted from the $S$. schenckii cell wall, a commercially available purified $\beta$-1,3-glucan or whole heat-killed $S$. schenckii yeasts (HKss). Additionally, a Dectin-1 antibody-mediated blockade assay was performed on day 10 postinfection to assess the participation of this receptor in cytokine secretion. Our results showed that Dectin- 1 expression by peritoneal macrophages was augmented on days 10 and 15 post-infection alongside elevated NO production and ex vivo secretion of IL-10, TNF- $\alpha$ and IL-1 $\beta$. The antibodymediated blockade of Dectin-1 inhibited cytokine production in both infected and non-infected mice, mainly after $\beta$-1,3-glucan stimulation. Our results suggest a role for Dectin-1 in triggering the immune response during $S$. schenckii infection.
\end{abstract}

(ㅇ 2017 Elsevier Ltd. All rights reserved.

\section{Introduction}

Sporotrichosis is an emergent subcutaneous mycosis affecting humans and other animals worldwide, but mainly in tropical and subtropical regions. This disease is caused by the traumatic inoculation of dimorphic fungi from the Sporothrix genus, including Sporothrix brasiliensis, Sporothrix globosa, Sporothrix mexicana, Sporothrix luriei, Sporothrix albicans, and Sporothrix schenckii sensu stricto $[1,2]$. These organisms are commonly found in the soil, surviving in different environmental conditions while developing

\footnotetext{
* Corresponding author. Department of Clinical Analysis, Faculty of Pharmaceutical Sciences of Araraquara, UNESP, Rod. Araraquara-Jaú - Km 1s/n Campos Ville, CEP: 14800-903, Araraquara, SP, Brazil.

E-mail address: carlosiz@fcfar.unesp.br (I.Z. Carlos).
}

resistance mechanisms against the host immune system [3,4]. Sporotrichosis is clinically characterized by cutaneous and subcutaneous lesions with regional lymphocutaneous dissemination. Systemic infections may also occur, mainly in immunosuppressed individuals [5].

Early activation of the immune system largely depends on pattern recognition receptors (PRRs), many of which involved in the recognition of fungal pathogens [6,7]. Several studies performed in our lab evidenced a role for different PRRs, including the Toll-like receptors (TLRs) 2 [8] and $4[9,10]$ and the NOD-like receptor (NLR) family member NLRP3 [11], as important innate components triggered during the $S$. schenckii infection. $\beta$-Glucans are a heterogeneous group of natural polysaccharides widely localized in the fungal cell wall and possessing immunemodulating activities through their ability to bind Dectin-1, a 
member of the C-type lectin receptor family [12]. This interaction is involved in the immune recognition of several pathogenic fungi, including Candida albicans, Aspergillus fumigatus, Pneumocystis carinii, Cryptococcus neoformans, Coccidioides spp. and Paracoccidiodes brasiliensis [13-15], leading to activation of phagocytosis and production of inflammatory mediators such as $\mathrm{H}_{2} \mathrm{O}_{2}, \mathrm{NO}$ and cytokines $[16,17]$. Furthermore, $\beta$-1,3-glucan and other Dectin1 ligands have been successfully used as adjuvants for various experimental antifungal vaccines [18]. Some studies showed that the $S$. schenckii infection triggers a series of mediators commonly associated to Dectin-1 activation [11,19].

A study using rats co-infected with Taenia taeniaeformis and S. schenckii or infected with $S$. schenckii alone, revealed a high Dectin-1 expression in the cutaneous lesions of co-infected rats only, as detected by immunohistochemical staining. The authors concluded that $S$. schenckii has a different molecular pattern and thus evokes anti-infection mechanisms other than Dectin-1 [20]. Regarding other immune mechanisms known to have a role in the host immune response to $S$. schenckii, a recent study evidenced that the Th17 response is important for an optimal control of the $\mathrm{S}$. schenckii infection in mice [21], whereas other studies have shown that the combination of itraconazole with $\beta-1,3$-glucan promoted an earlier regression of sporotrichosis lesions in comparison with the antifungal therapy alone $[22,23]$.

The available information on the role played by Dectin-1 in sporotrichosis is scarce. Therefore, here we aimed to assess Dectin1 expression by macrophages and the activation of some related antifungal mechanisms during the $S$. schenckii sensu stricto infection to better understand the role of this receptor in a murine model of systemic infection by this pathogen.

\section{Materials and methods}

\subsection{Microorganism and culture conditions}

Sporothrix schenckii sensu stricto ATCC 16345 was kindly provided by the Oswaldo Cruz Foundation (Rio de Janeiro, Brazil). For mice infection and heat-killed $S$. schenckii yeast (HKss) preparation, a piece of mycelium grown on Mycosel ${ }^{\mathrm{TM}}$ (BD Biosciences) agar tubes was transferred to brain-heart infusion broth (BHI, Difco) and then cultured for 7 days at $37{ }^{\circ} \mathrm{C}$ in order to achieve a near $100 \%$ mycelium-to-yeast conversion during the logarithmic phase of growth. Before use, the culture was filtered through sterile gauze to remove mycelium fragments.

\subsection{Heat-killed S. schenckii preparation}

Yeasts were harvested from the BHI culture by centrifugation, washed twice and adjusted to $2.5 \times 10^{8}$ yeasts $/ \mathrm{mL}$ in sterile phosphate buffered saline (PBS), $\mathrm{pH}$ 7.4. Aliquots of this suspension were incubated for $1 \mathrm{~h}$ in a $60{ }^{\circ} \mathrm{C}$ water bath and then stored at $2-8{ }^{\circ} \mathrm{C}$ until use. The efficiency of the heat-killing process was assessed by plating aliquots on MycoselТM agar and checking for colony forming units (CFU) growth before use [21].

\subsection{Alkali-insoluble fraction (F1)}

The alkali-insoluble fraction was isolated as described previously [24]. Briefly, yeast cell walls were suspended in $1 \mathrm{~N} \mathrm{NaOH}$ and gently stirred for $1 \mathrm{~h}$ at room temperature. After centrifugation at $5000 \times \mathrm{g}$ for $10 \mathrm{~min}$, the supernatant was collected and the procedure was repeated four times. The alkali-insoluble sediment was washed with water until it reached $\mathrm{pH} 7.0$ and was then washed with ethanol, acetone and diethyl ether, in that order. The resulting white powder was called the alkali-insoluble fraction (F1).

\subsection{Animals and experimental design}

Male Balb/c mice, 5-7 weeks old, were purchased from "Centro Multidisciplinary para Investigação Biológica na Área da Ciência de Animais de Laboratório" (CEMIB), UNICAMP University (Brazil). Five mice per group were housed in microisolator cages and maintained in specific pathogen-free (SPF) conditions. Animals were intraperitoneally (i.p.) inoculated with $10^{6} \mathrm{~S}$. schenckii yeasts in PBS or with an equal volume of PBS alone. The animals were euthanized on days 5,10 and 15 post-infection. All animal procedures were performed according to the guidelines of the Brazilian College of Animal Experimentation (COBEA) and were approved by the research ethics committee of Araraquara's School of Pharmaceutical Sciences from UNESP University (CEUA/FCF/CAr n 02/2015).

\subsection{Peritoneal exudate cells}

Thioglycollate-elicited peritoneal exudate cells (PECs) were harvested from mice 3 days after the i.p. inoculation with 3\% sodium thioglycollate, which was performed by washing the peritoneal cavity with $5.0 \mathrm{~mL}$ of cold PBS. The cells were washed twice by centrifugation at $300 \times \mathrm{g}$ for $5 \mathrm{~min}$ at $4{ }^{\circ} \mathrm{C}$ with PBS and then resuspended in complete RPMI medium (cRPMI). PECs were counted in a Neubauer chamber and adjusted to $5 \times 10^{6}$ macrophages $/ \mathrm{mL}$.

\subsection{Assessment of the systemic fungal load}

Spleens were aseptically removed, macerated in PBS and passed through a $100 \mu \mathrm{m}$ cell strainer. The systemic fungal load was determined by counting the CFU grown on Mycosel ${ }^{\mathrm{TM}}$ agar plates after the spread-plating of a previously determined dilution of the spleen macerate.

\subsection{Flow cytometry}

In all staining procedures, only freshly isolated, unstimulated PECs were used. Briefly, the cells were extracellularly labeled with the following monoclonal antibodies $(\mathrm{mAb})$ : anti-CD11b FITC (clone M1/70), anti-F4/80 APC (clone BM8), and anti-Dectin-1 PE (clone bg1fpj), all from eBioscience. Unspecific staining was controlled by pre-incubating all samples with anti-CD16/CD32. Alternatively, the cells were stained for CD11b and F4/80 only and incubated with the PE isotype control. Events were acquired using a BD Accuri C6 flow cytometer (BD Biosciences).

\subsection{Nitric oxide production}

Nitric oxide (NO) production by PECs was assessed by the Griess method [25]. NO concentrations were calculated from a previously established standard curve using known concentrations of sodium nitrite. Absorbance was read in a UV/visible microplate spectrophotometer (Multiskan Ascent, Labsystems) at $540 \mathrm{~nm}$.

\subsection{Ex vivo secretion of cytokines}

PECs were cultured for $24 \mathrm{~h}$ at $37{ }^{\circ} \mathrm{C}$ and $5 \% \mathrm{CO}_{2}$ on flat-bottom 48 -well tissue culture plates in the presence of $1 \mathrm{~mL}$ of cRPMI containing the following stimuli: $\beta$-1,3-glucan from Saccharomyces cerevisiae (Sigma, $100 \mu \mathrm{g} / \mathrm{mL}), \mathrm{F} 1(100 \mu \mathrm{g} / \mathrm{mL})$, HKss $\left(2,5 \times 10^{7} / \mathrm{mL}\right)$. LPS $(10 \mu \mathrm{g} / \mathrm{mL})$ or CRPMI alone were used as the positive or negative control, respectively. Cytokines were measured by ELISA (eBioscience) according to the manufacturer's instructions. 


\subsection{Dectin-1 antibody-mediated blockade assays}

In an independent experiment, PECs from S. schenckii-infected and non-infected mice were used for a Dectin- 1 antibody-mediated blockade assay aiming to evaluate the impact of Dectin-1 engagement in macrophage activation on day 10 post-infection. The PECs were seeded at $1 \times 10^{6}$ cells $/ \mathrm{mL}$ in a 24 -well plate. After a 2 -h preincubation, the cells were incubated with $10 \mu \mathrm{g} / \mathrm{mL}$ of an antiDectin- $1 \mathrm{mAb}$ (eBiosciense) for $30 \mathrm{~min}$ at $37{ }^{\circ} \mathrm{C}$ and then added with $1 \mathrm{~mL}$ of cRPMI containing the following stimuli for another 24 h: $\beta$-1,3-glucan $(100 \mu \mathrm{g} / \mathrm{mL})$, F1 $(100 \mu \mathrm{g} / \mathrm{mL})$, HKss $\left(2,5 \times 10^{7} /\right.$ $\mathrm{mL})$, LPS $(10 \mu \mathrm{g} / \mathrm{mL})$, or cRPMI only. The supernatants were collected and used to determine the concentration of IL-10, TNF- $\alpha$ and IL- $1 \beta$ by ELISA.

\subsection{Role of Dectin-1 in the phagocytosis of S. schenckii yeast}

Peritoneal exudate was collected as described above. The macrophage monolayers from infected and un-infected mice were incubated for $1 \mathrm{~h}$ for adherence. They were then treated with $10 \mu \mathrm{g} /$ $\mathrm{mL}$ of anti-dectin-1. After $1 \mathrm{~h}$ of incubation at $37{ }^{\circ} \mathrm{C}$, they were incubated with live $S$. schenckii yeast, resulting in a 1:5 ratio of S. schenckii-to-macrophages. Control with cytochalasin D final concentration, $10 \mu \mathrm{M}$, Sigma-Aldrich, St. Louis, MO (to prevent internalization) or vehicle control were included. All assays were done with five wells per condition. After incubation, the culture medium was carefully removed and the monolayers were washed with $1 \mathrm{~mL}$ of distilled water to lyse macrophages. One hundred

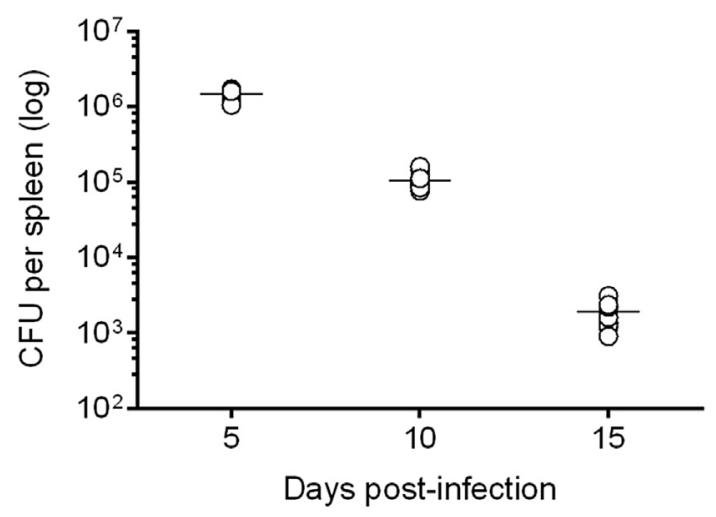

Fig. 1. Assessment of spleen fungal load. Mice were i.p. inoculated with $10^{6} \mathrm{~S}$. schenckii yeasts. On the indicated days, mice were euthanized and the spleens were removed for assessment of the fungal load in the spleen. microliters of cell homogenates were assayed for the presence of viable yeasts in Petri dishes containing Mycosel agar, incubated at $30{ }^{\circ} \mathrm{C}$ for 5 days. The colony forming units (CFU) per well $(1 \mathrm{~mL})$ were determined by counting the number of fungi growing on the culture dish. Performed with five wells per condition. The occurrence of effective phagocytosis of $S$. schenckii yeast by macrophages was controlled in parallel by incubation under the same conditions on glass slides and microscope.

\subsection{Statistical analysis}

Statistical analysis was performed in GraphPad Prism ver. 6.01 using one- or two-way analysis of variance (ANOVA) with Tukey or Sidak's multiple comparisons test, respectively. Student's t-test was also used where indicated. The confidence interval was set at $95 \%$ for all tests.

\section{Results}

\subsection{Sporothrix schenckii systemic infection model}

According to previous studies, the days 5, 10 and 15 postinfection corresponded to the peak of animal susceptibility, the ongoing elimination of the fungus, and the final clearance of the infection, respectively [21]. This result confirmed that model was adequately reproduced here (Fig. 1).

\subsection{Dectin-1 expression by PECS}

The frequency of Dectin-1-expressing cells, as well as the expression level of this receptor, was significantly increased among peritoneal macrophages on days 10 and 15 post-infection when compared to non-infected mice (Fig. 2). The presented results indicate that Dectin-1 expression is upregulated during the S. schenckii infection, suggesting a role for Dectin-1-triggered immune responses in controlling this infection.

\subsection{NO production}

NO production by peritoneal macrophages from S. schenckiiinfected mice was increased upon exposure to all the stimuli, but especially F1 and HKss. The purified $\beta$-1,3-glucan-induced NO production, albeit significant, was comparatively low during the entire experimental period, suggesting that NO production during the $S$. schenckii infection is triggered not only by recognition of $\beta$ glucan but also by other components of the fungal cell wall (Fig. 3).

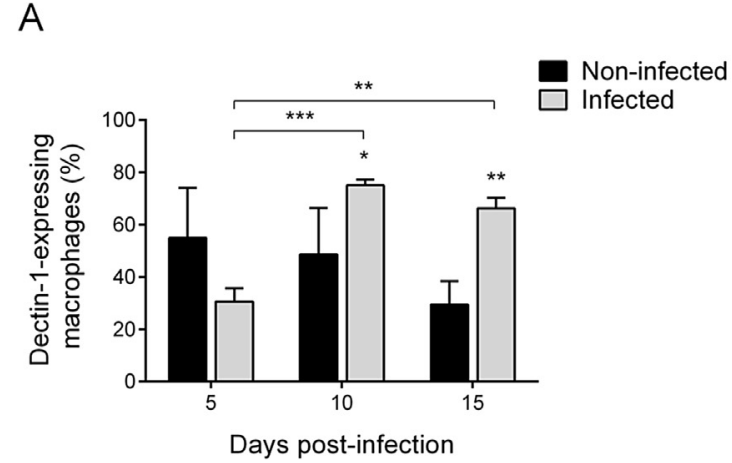

B

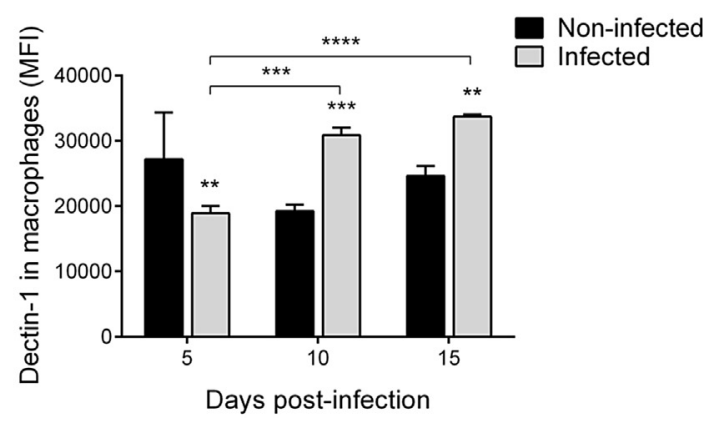

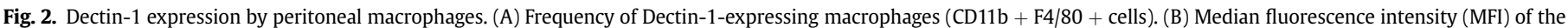

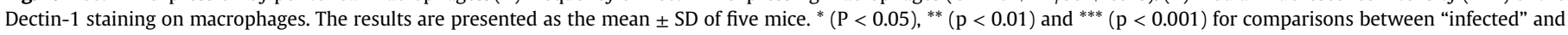
"non-infected" mice at each respective time point. 
Day 5

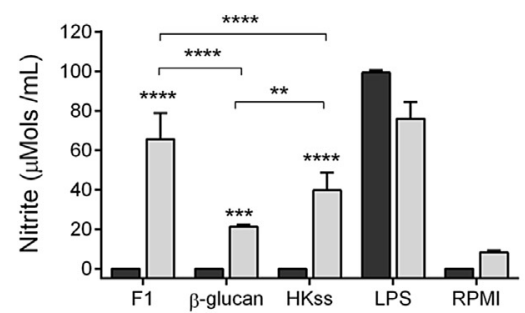

Day 10

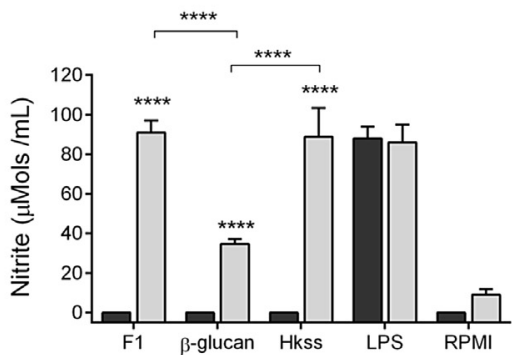

Day 15 Non-infected Infected

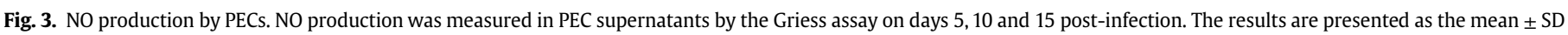
of five mice. ${ }^{* *}(\mathrm{P}<0.01),{ }^{* * *}(\mathrm{p}<0.001)$ and ${ }^{* * * *}(\mathrm{p}<0.0001)$ for comparisons between "infected" and "non-infected" mice treated with the same stimulus or as indicated.

\subsection{Cytokine detection in culture supernatant}

Except for $\beta$-1,3-glucan, all the other stimuli were able to induce, to a greater or lesser extent, the secretion of IL-10, TNF- $\alpha$ and IL-1 $\beta$ during the entire studied period. When challenged with $\beta-1,3-$ glucan, peritoneal macrophages from $S$. schenckii-infected mice were able to secrete significant amounts of IL- 10 only on days 5 and 10 post-infection (Fig. $4 \mathrm{~A}$ and B), and of IL-1 $\beta$ only on days 10 and 15 post-infection (Fig. $4 \mathrm{H}$ and I). On the other hand, the $\beta-1,3-$ glucan-induced TNF- $\alpha$ secretion was significant only on day 10 post-infection (Fig. 4E), although the mean secretion on day 15 post-infection was increased more than 4 times as compared to unstimulated cells from infected mice or $\beta-1,3$-glucan-stimulated cells from non-infected ones. Except for the secretion of IL-10 on day 5 post-infection and of IL- $1 \beta$ on day 15 post-infection, the same previous pattern was observed for F1 and HKss, which were more efficient stimuli than $\beta-1,3$-glucan as inducers of the ex vivo secretion of IL-10, IL-1 $\beta$ and TNF- $\alpha$ by macrophages from infected mice. Furthermore, contrary to IL-10 and TNF- $\alpha$, IL- $1 \beta$ secretion, although still significant, was clearly reduced on day 15 postinfection.

\subsection{Dectin-1 antibody-mediated blockade assay}

The antibody-mediated blockade of Dectin-1 clearly inhibited the secretion of IL-10, IL-1 $\beta$ and TNF- $\alpha$ in response to HKss, F1 and $\beta$-1,3-glucan by peritoneal macrophages from $S$. schenckii-infected mice. On the other hand, TNF- $\alpha$ secretion only was inhibited, and solely in response to $\beta$-1,3-glucan stimulation, when using macrophages from non-infected mice (Fig. 5). It is noteworthy that, in general, the strongest inhibition was reached upon $\beta$-1,3-glucan stimulation, given its role as a specific Dectin-1 ligand, suggesting HKss and F1 may be engaging other receptors in addition to Dectin1. These results indicate that Dectin-1 plays an important role in macrophage activation during $S$. schenckii infection.

\subsection{Role of Dectin-1 in the phagocytosis of S. schencki yeast}

The absolute amounts of phagocytized $\mathrm{S}$. schenckii yeast (calculated as the difference between the CFU of wells without and with cytochalasin D) was determined. As expected, a higher count of intracellular CFU was observed in infected mice in comparison with non-infected. However, it was also observed a reduction of phagocytized yeasts in the wells with anti-Dectin- 1 antibodies of both groups. Fig. 6 depict the reduction of intracellular CFU by Dectin1 blocking expressed as absolute count (Fig. 6A) and in percent (Fig. 6b). The presence of intracellular yeast was microscopically confirmed (Suplementary Fig. 2).

\section{Discussion}

Dectin-1 is a cell surface innate immune receptor that plays an important role in immunity against fungal pathogens. Netea et al. [26] showed that $C$. albicans induces cytokine production by binding to different macrophage receptors, each one recognizing a different structure on the Candida cell wall. Mannan polymers are recognized by the mannose receptor, while $\beta$-1,3-glucan are recognized by Dectin-1 and TLR-2, showing that the collaborative recognition of distinct fungal components by different classes of innate immune receptors is critical for inflammatory response development [27].

The engagement of Dectin- 1 by $\beta-1,3$-glucan leads to activation of phagocytosis and stimulates production of fungicidal and pro- or anti-inflammatory mediators, including reactive oxygen species (ROS), cytokines such as IL- $1 \beta$, TNF- $\alpha$, IL-10, and chemokines [15-17]. These early innate immunity events play a role in determining the development of subsequent antifungal adaptive immune responses, such as the polarization of naïve Th cells into effector IL-17 + Th cells [28-30].

The fungi cell wall polysaccharides include glucose, mannose, galactose, glucans, galactomannans, and chitin polymers. The alkali-insoluble glucans, which compose the $\mathrm{F} 1$ fraction, contain $\beta(1,3), \beta(1,6)$ and $\beta(1,4)$ linkages in a proportion of $66 \%, 29 \%$ and $5 \%$, respectively $[24,31]$. Here, we show that the frequency of Dectin-1expressing cells, as well as the expression level of this receptor, was increased among peritoneal macrophages on days 10 and 15 postinfection, suggesting this receptor may be participating in $S$. schenckii recognition. This result contradicts a previous study where the authors suggested that Dectin-1 does not participate in S. schenckii recognition [20]. Differences in experimental design and animal model (rats versus mice), may account for this.

The secretion of IL-10 during the resolution stage of the infection (day 15 post-infection) and of TNF- $\alpha$ and IL- $1 \beta$ during the peak of animal susceptibility (day 5 post-infection) do not appear to depend on $\beta$-1,3-glucan recognition but on additional components of the $S$. schenckii cell wall present in the F1 fraction used by us. Moreover, it is possible to suggest that secretion of IL-10 during the peak of animal susceptibility and of IL- $1 \beta$ during the resolution stage of the infection depend on the recognition of $S$. schenckii $\beta$ 1,3-glucans since our results were virtually identical across all the three stimuli. In any case, it is important to consider that, although we used an equal amount of purified $\beta$-1,3-glucan and F1 plus the fact that most glucans present in F1 are of the $\beta(1,3)$ type, there are still enough differences between the preparations to justify at least 

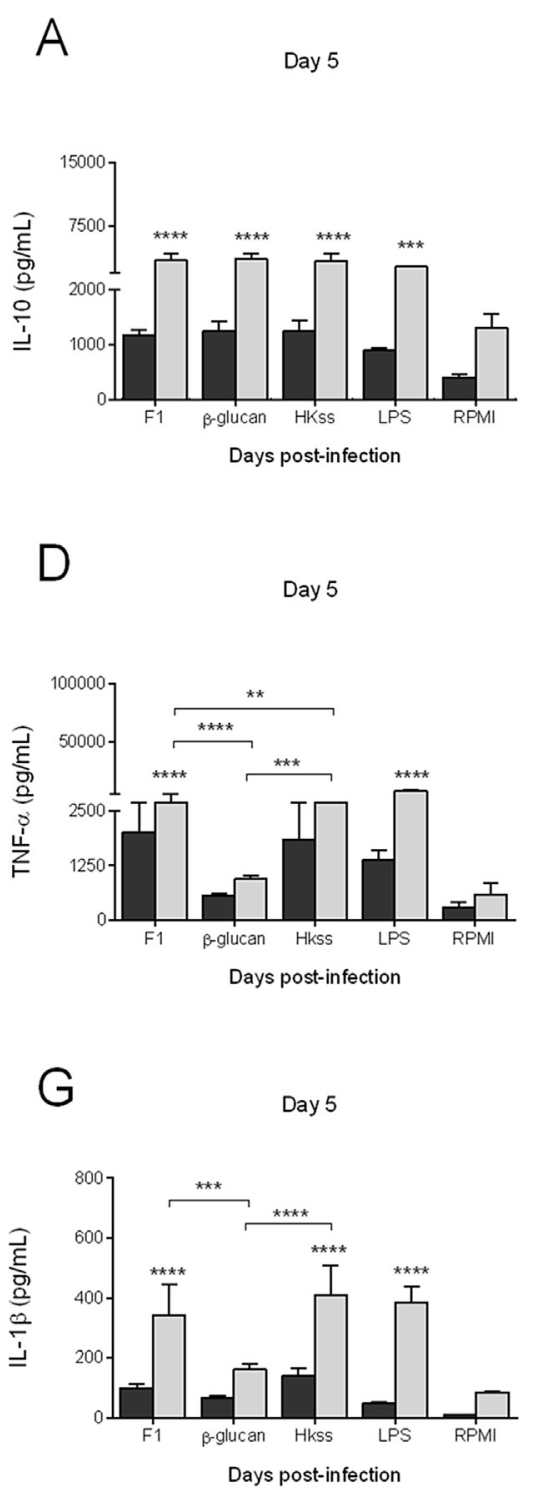
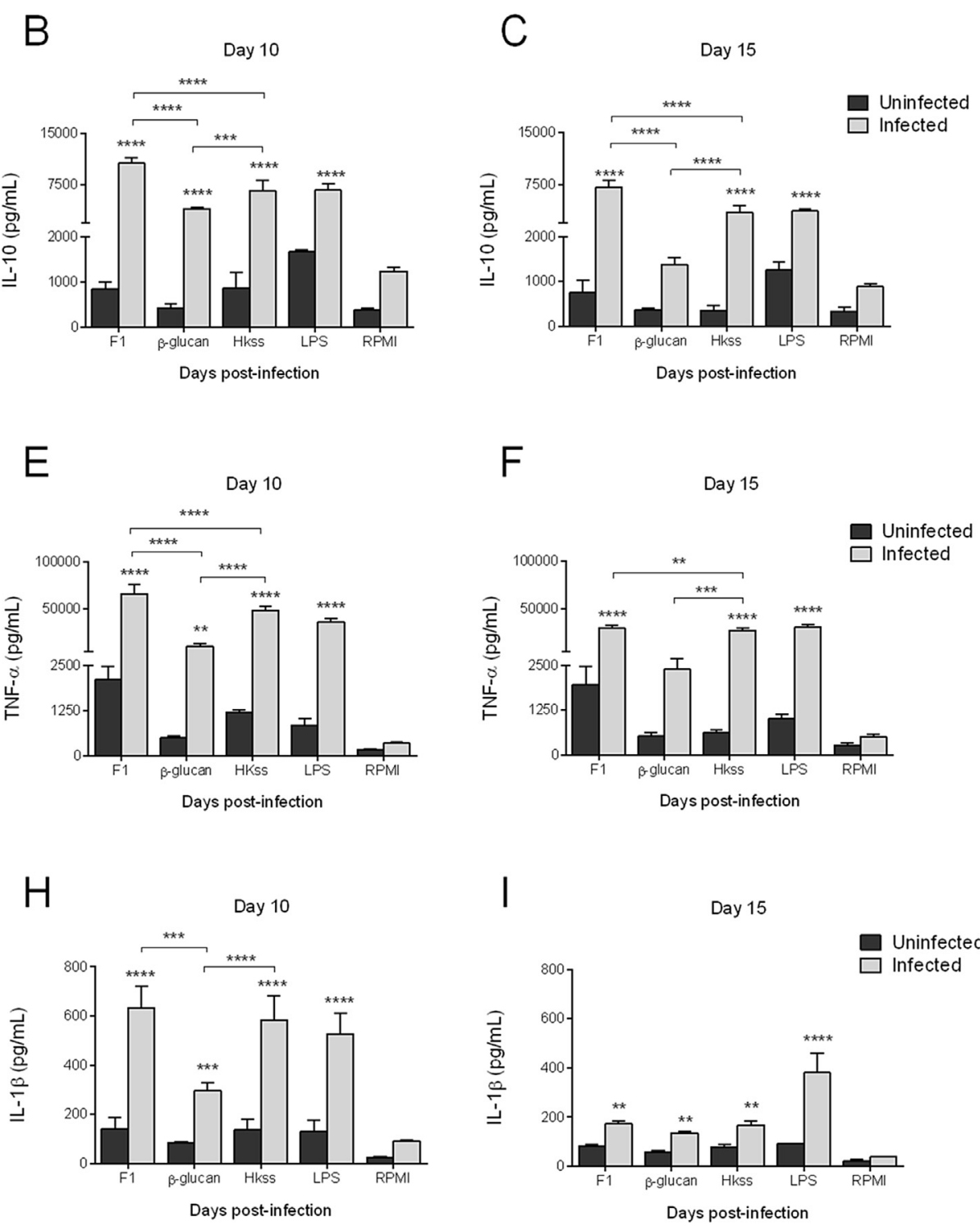

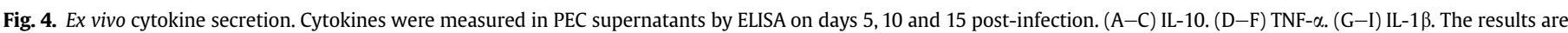

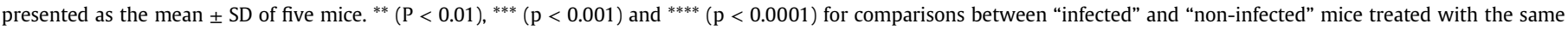
stimulus or as indicated.

some of the observed differences, namely: the presence of $\beta(1,6)$ and $\beta(1,4)$ glucans, the lower concentration of $\beta-1,3$-glucan and the presence of other non-glucan components in F1. Future studies will clearly benefit from using more purified preparations containing specific components of the $S$. schenckii cell wall.

To confirm the role of Dectin-1 in the proinflammatory response triggered by S. schenckii, peritoneal macrophages from infected and non-infected mice were challenged with different stimuli, including $\beta$-1,3-glucan, in the presence or absence of an anti-Dectin-1 mAb. When Dectin-1 was blocked, secretion of the proinflammatory cytokines TNF- $\alpha$ and IL-1 $\beta$ and the antiinflammatory cytokine IL-10 by HKss, F1 or $\beta-1,3$-glucan were strongly suppressed. This indicates that Dectin-1 is deeply involved in macrophage activation upon exposure to S. schenckii, although, as already discussed, other PRRs also participate.

Phagocytosis is an important innate mechanism in sporotrichosis. However, once S. schenckii yeast have been phagocytosed, they are able to survive within the phagocytic cells. Survival of virulent $S$. schenckii yeast cells after phagocytosis relies on diverse detoxification including the ergosterol peroxide synthesis [32]. Binding of $\beta-1-3$ glucan by dectin- 1 has been shown to be essential for phagocytosis of $C$. albicans [33] and Aspergillus fumigatus conidia [34]. These findings prompted us to analyse whether dectin- 1 is also involved in the phagocytosis of $S$. schenckii yeast. At a concentration of $10 \mu \mathrm{g} / \mathrm{mL}$ of anti-dectin- 1 antibody reduced the phagocytic uptake of yeast by approximately $60 \%$ in infected and non-infected mice. And this reduction suggest that Dectin-1 is involved, together with other receptors in the phagocytic process on this infection.

According to recent studies, the innate immunity can be "trained", thereby acquiring a higher capacity to respond to invasive infections $[35,36]$. It has been reported that exposure to a small load of $C$. albicans was able to induce protection against reinfection with this fungus in mice deficient in functional T and B cells [37]. These authors also described an in vitro assay where monocytes were pre-incubated with heat-killed $C$. albicans and then exposed to different secondary stimuli, including $\beta$-1,3-glucan, leading to enhanced cytokine production. It would be interesting to assess if a 

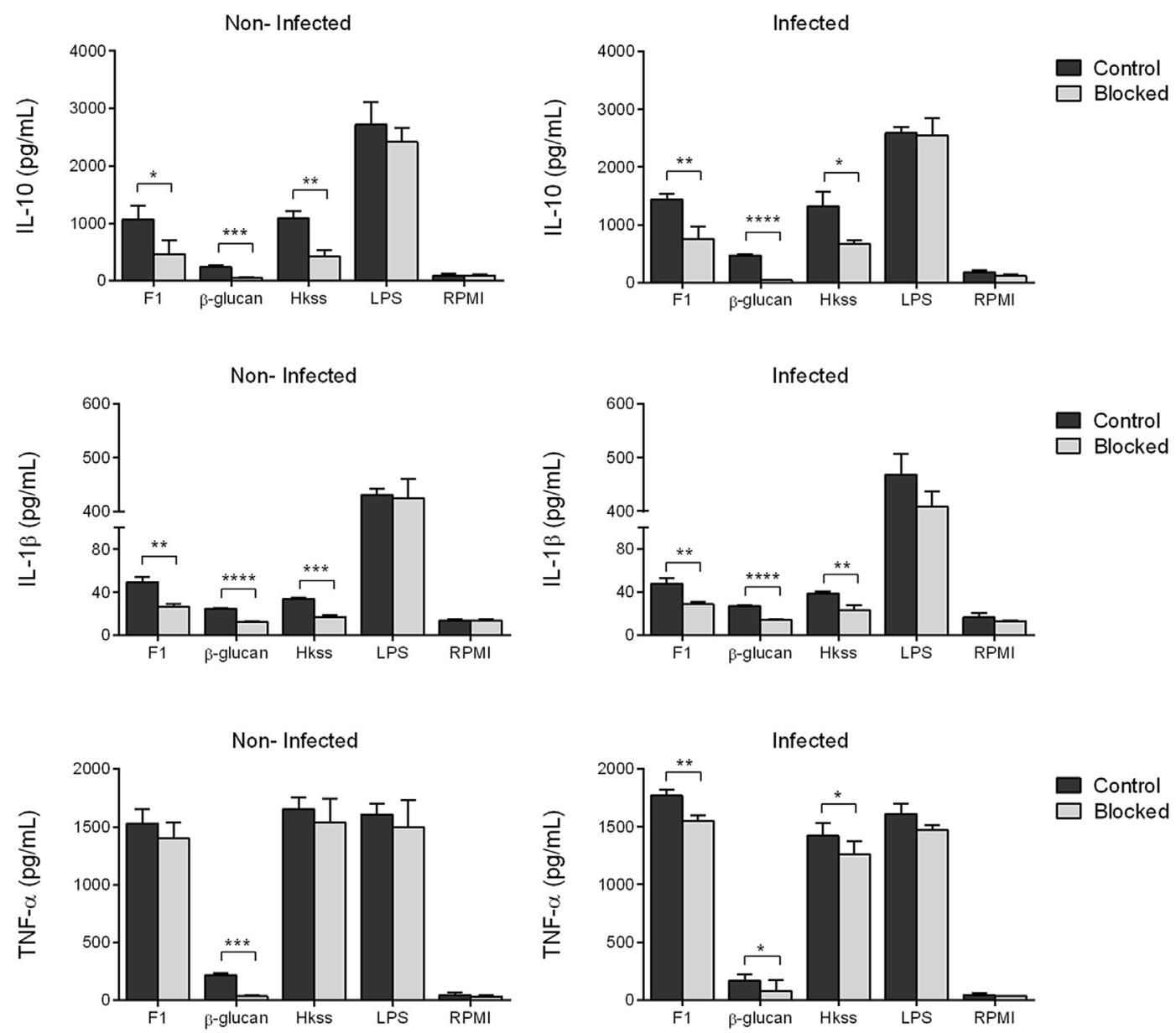

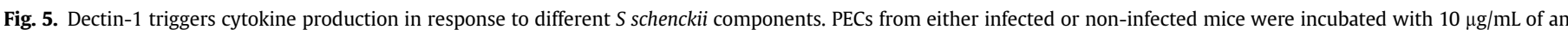

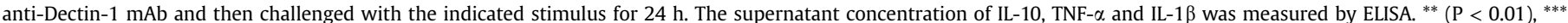
$(\mathrm{p}<0.001)$ and ${ }^{* * * *}(\mathrm{p}<0.0001)$ for comparisons between "blocked" and "non-blocked (control)" cells.

A

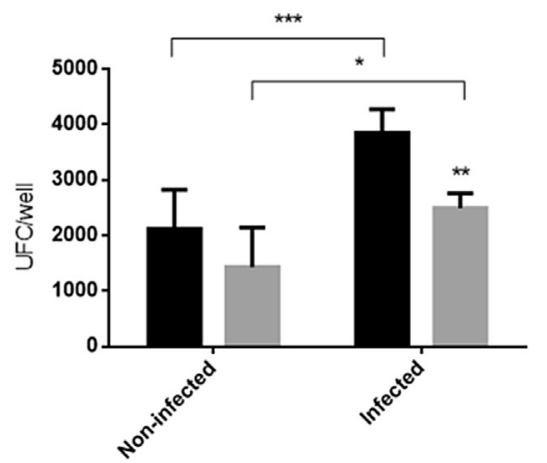

B

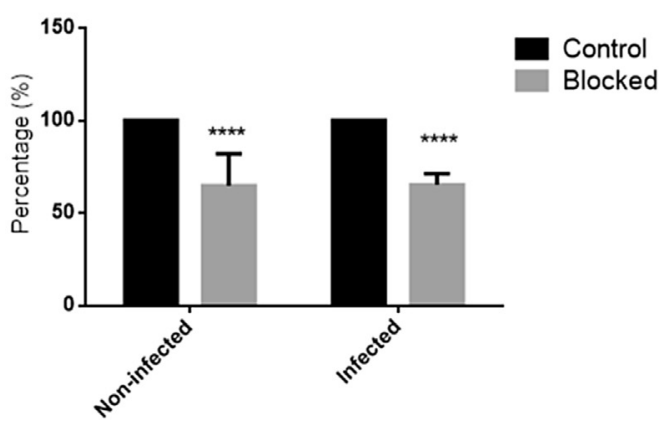

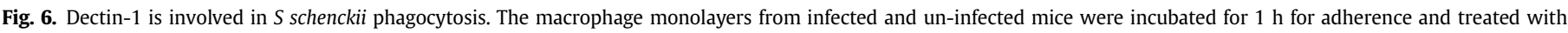

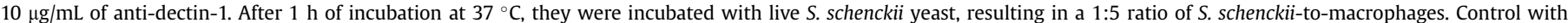

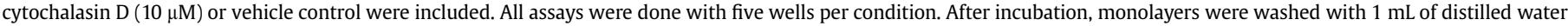

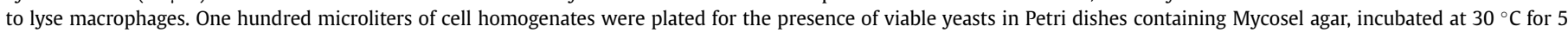

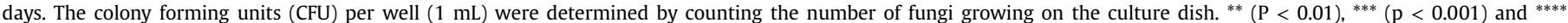
( $p<0.0001)$ for comparisons between "blocked" and "non-blocked (control)" cells.

trained state can be evoked in response to $S$. schenckii infection in a Dectin-1-dependent manner. Efforts in this area would be very useful for the development of immunomodulatory drugs and vaccines against sporotrichosis, an area of great current interest [38-40].

\section{Conclusion}

In summary, our data greatly contributes to understand the way in which $S$. schenckii is recognized by and stimulates cells of the innate immune system and for understanding the pathophysiology 
of sporotrichosis. On one hand, we demonstrated that recognition of $\beta-1,3$-glucan and other fungal components by Dectin- 1 increases the cytokine release induced by the $S$. schenckii infection. To the best of our knowledge, this is the first attempt to determine the role of Dectin-1 in the development of immune response against S. schenckii. Further studies using Dectin-1 knockout animals and assessing the activation of related signaling pathways will help to deepen our understanding of these mechanisms.

\section{Conflicts of interest}

The authors declare no commercial or financial conflicts of interest.

\section{Acknowledgments}

This work was supported by Fundação de Amparo à Pesquisa do Estado de São Paulo (FAPESP, grant $n^{\circ}$. 2012/24187-0).

\section{Appendix A. Supplementary data}

Supplementary data related to this article can be found at http:// dx.doi.org/10.1016/j.micpath.2017.06.025.

\section{References}

[1] I.Z. Carlos, A. Batista-Duharte, Sporotrichosis: an emergent disease, in: I.Z. Carlos (Ed.), Sporotrichosis. New Developments and Future Prospects, Springer International Publishing, Switzerland, 2015, pp. 1-23.

[2] H.M. Mora-Montes, S. Ada Dantas, E. Trujillo-Esquivel, A.R. de Souza Baptista, L.M. Lopes-Bezerra, Current progress in the biology of members of the Sporothrix schenckii complex following the genomic era, FEMS Yeast Res. 15 (6) (2015) pii: fov065.

[3] M.D. Téllez, A. Batista-Duharte, D. Portuondo, C. Quinello, R. Bonne-Hernández, I.Z. Carlos, Sporothrix schenckii complex biology: environment and fungal pathogenicity, Microbiology 160 (Pt11) (2014) 2352-2365.

[4] A. Batista-Duharte, D.T. Martínez, D.B. da Graça Sgarbi, I.Z. Carlos, Environmental conditions and fungal pathogenicity, in: I.Z. Carlos (Ed.), Sporotrichosis. New Developments and Future Prospects, Springer International Publishing, Switzerland, 2015, pp. 53-72.

[5] M.B. Barros, R. de Almeida Paes, A.O. Schubach, Sporothrix schenckii and sporotrichosis, Clin. Microbiol. Rev. 24 (4) (2011) 633-654.

[6] A. Plato, S.E. Hardison, G.D. Brown, Pattern recognition receptors in antifungal immunity, Semin. Immunopathol. 37 (2) (2015) 97-106.

[7] P. Alegranci, L.C. de Abreu Ribeiro, L.S. Ferreira, T.C. Negrini, D.C. Maia, A. Tansini, A.C. Gonçalves, M.C. Placeres, I.Z. Carlos, The predominance of alternatively activated macrophages following challenge with cell wall peptide-polysaccharide after prior infection with Sporothrix schenckii, Mycopathologia 176 (1-2) (2013) 57-65.

[8] T.C. Negrini, L.S. Ferreira, P. Alegranci, R.A. Arthur, P.P. Sundfeld, D.C. Maia, L.C. Spolidorio, I.Z. Carlos, Role of TLR-2 and fungal surface antigens on innate immune response against Sporothrix schenckii, Immunol. Invest. 42 (1) (2013) $36-48$.

[9] M.F. Sassá, A.E. Saturi, L.F. Souza, L.C. Ribeiro, D.B. Sgarbi, I.Z. Carlos, Response of macrophage Toll-like receptor 4 to a Sporothrix schenckii lipid extract during experimental sporotrichosis, Immunology 128 (2) (2009) 301-309.

[10] M.F. Sassá, L.S. Ferreira, L.C. de Abreu Ribeiro, I.Z. Carlos, Immune response against Sporothrix schenckii in TLR-4-deficient mice, Mycopathologia 174 (2012) 21-30.

[11] A.C. Gonçalves, D.C. Maia, L.S. Ferreira, L.G. Monnazzi, P. Alegranci, M.C. Placeres, A. Batista-Duharte, I.Z. Carlos, Involvement of major components from Sporothrix schenckii cell wall in the caspase 1 activation, nitric oxide and cytokines production during experimental sporotrichosis, Mycopathologia 179 (1-2) (2015) 21-30.

[12] S.V. Tsoni, G.D. Brown, Beta-glucans and Dectin-1, Ann. N. Y. Acad. Sci. 1143 (2008) 45-60.

[13] R.A. Drummond, G.D. Brown, The role of Dectin-1 in the host defense against fungal infections, Curr. Opin. Microbiol. 14 (4) (2011) 392-399.

[14] T.F. Bachiega, L.A. Dias-Melicio, R.K. Fernandes, H. de Almeida Balderramas, D.R. Rodrigues, V.F. Ximenes, A.M. de Campos Soares, Participation of Dectin-1 receptor on NETs release against Paracoccidioides brasiliensis: role on extracellular killing, Immunobiology 221 (2) (2016) 228-235.

[15] C. Feriotti, S.B. Bazan, F.V. Loures, E.F. Araújo, T.A. Costa, V.L. Calich, Expression of Dectin-1 and enhanced activation of NALP3 inflammasome are associated with resistance to paracoccidioidomycosis, Microbiol. 6 (2015) 913.

[16] H.S. Goodridge, A.J. Wolf, D.M. Underhill, Beta-glucan recognition by the innate immune system, Immunol. Rev. 230 (2009) 38-50.

[17] S.E. Hardison, G.D. Brown, C-type lectin receptors orchestrate antifungal immunity, Nat. Immunol. 13 (9) (2012) 817-822.

[18] D.L. Portuondo, L.S. Ferreira, A.C. Urbaczek, A. Batista-Duharte, I.Z. Carlos Adjuvants and delivery systems for antifungal vaccines: current state and future developments, Med. Mycol. 53 (1) (2015) 69-89.

[19] D.C.G. Maia, A.C. Gonçalves, L.S. Ferreira, F.A. Manente, D.L. Portuondo, J.C.R. Vellosa, M.C. Polesi, A. Batista-Duharte, I.Z. Carlos, Response of cytokines and hydrogen peroxide to Sporothrix schenckii exoantigen in systemic experimental infection, Mycopathologia 181 (3-4) (2016) 207-215.

[20] X. Zhang, J. Zhang, H. Huang, R. Xue, X. Hu, M. Li, Y. Zhong, L. Yuan, Taenia taeniaeformis in rat favors protracted skin lesions caused by Sporothrix schenckii infection: dectin-1 and IL-17 are dispensable for clearance of this fungus, PLoS One 7 (12) (2012) e52514.

[21] L.S. Ferreira, A.C. Gonçalves, D.L. Portuondo, D.C. Maia, M.C. Placeres, A. Batista-Duharte, I.Z. Carlos, Optimal clearance of Sporothrix schenckii requires an intact Th17 response in a mouse model of systemic infection, Immunobiology 220 (8) (2015) 985-992.

22] K.A. Guterres, C.B. de Matos, L.G. Osório, I.D. Schuch, M.B. Cleff, The use of (13) $\beta$-glucan along with itraconazole against canine refractory sporotrichosis, Mycopathologia 177 (3-4) (2014) 217-221.

[23] A.A. Martins, Experimental Systemic Sporotrichosis: Evaluation in Vivo $\beta$ (1-3) Glucan and in Association to Itraconazole in Murine Model Universidade Federal do Rio Grande do Sul, Faculdade de Veterinária. Programa de Pós-Graduação em Ciências Veterinárias Porto Alegre, RS, 2012. Doctoral Thesis, http://www.lume.ufrgs.br/handle/10183/49694.

[24] F. Kanetsuna, L.M. Carbonell, R.E. Moreno, J. Rodrigues, Cell wall composition of the yeast and mycelial forms of Paracoccidioides brasiliensis, J. Bacteriol. 97 (1969) 1036-1041.

25] L.C. Green, D.A. Wagner, J. Glogowski, P.L. Skipper, J.S. Wishnok, S.R. Tannenbaum, Analysis of nitrate, nitrite, and [15N] nitrate in biological fluids, Anal. Biochem. 126 (1982) 131-138.

[26] M.G. Netea, G. Ferwerda, C.A. Van der Graaf, J.W. Van der Meer, B.J. Kullberg, Recognition of fungal pathogens by Toll-like receptors, Curr. Pharm. Des. 12 (32) (2006) 4195-4201.

[27] K.M. Dennehy, J.A. Willment, D.L. Williams, G.D. Brown, Reciprocal regulation of IL-23 and IL-12 following co-activation of Dectin-1 and TLR signaling pathways, Eur. J. Immunol. 30 (2009) 1379-1386.

[28] F. Osorio, S. Leibundgut-Landmann, M. Lochner, K. Lahl, T. Sparwasser, G. Eberl, DC activated via Dectin-1 convert Treg into IL-17 producers, Eur. J. Immunol. 38 (2008) 3274-3281.

[29] A. Carvalho, G. Giovannini, A. De Luca, C. D'Angelo, A. Casagrande, R.G. Iannitti, Dectin-1 isoforms contribute to distinct Th1/Th17 cell activation in mucosal candidiasis, Cell Mol. Immunol. 9 (2012) 276-286.

[30] P.R. Taylor, S.V. Tsoni, J.A. Willment, K.M. Dennehy, M. Rosas, H. Findon, Dectin-1 is required for $\beta$-glucan recognition and control of fungal infection, Nat. Immunol. 8 (2007) 31-38.

[31] J.O. Previato, A.J. Philip, R.H. Gorin, L.R. Travassos, Soluble and insoluble glucans from different cell types of the human pathogen Sporothrix schenckii Exper Mycol. 3 (1979) 92-100.

32] D.B. Sgarbi, A.J. da Silva, I.Z. Carlos, C.L. Silva, J. Angluster, C.S. Alviano, Isolation of ergosterol peroxide and its reversion to ergosterol in the pathogenic fungus Sporothrix schenckii, Mycopathologia 139 (1) (1997) 9-14.

[33] B.N. Gantner, R.M. Simmons, S.J. Canavera, S. Akira, D.M. Underhill, Collaborative induction of inflammatory responses by dectin-1 and Toll-like receptor 2, J. Exp. Med. 197 (2003) 1107-1117.

[34] K. Luther, A. Torosantucci, A.A. Brakhage, J. Heesemann, F. Ebel, Phagocytosis of Aspergillus fumigatus conidia by murine macrophages involves recognition by the dectin-1 beta-glucan receptor and Toll-like receptor 2, Cell Microbiol. 9 (2) (2007) 368-381.

[35] M.G. Netea, J. Quintin, J.W. Van der Meer, Trained immunity: a memory for innate host defense, Cell Host Microbe 9 (5) (2011) 355-361.

[36] J.W. Van der Meer, L.A. Joosten, N. Riksen, M.G. Netea, Trained immunity: a smart way to enhance innate immune defence, Mol. Immunol. 68 (1) (2015) $40-44$.

[37] J. Quintin, S. Saeed, J.H. Martens, E.J. Giamarellos-Bourboulis, D.C. Ifrim, C. Logie, L. Jacobs, T. Jansen, B.J. Kullberg, C. Wijmenga, L.A. Joosten, R.J. Xavier, J.W. Van der Meer, H.G. Stunnenberg, M.G. Netea, Candida albicans infection affords protection against reinfection via functional re-programming of monocytes, Cell Host Microbe 12 (2) (2012) 223-232.

[38] D.L. Portuondo, A. Batista-Duharte, L.S. Ferreira, D.T. Martínez, M.C. Polesi R.A. Duarte, A.C. de Paula E Silva, C.M. Marcos, A.M. Almeida, I.Z. Carlos, A cell wall protein-based vaccine candidate induces protective immune response against Sporothrix schenckii infection, Immunobiology 221 (2) (2016) 300-309.

[39] A. Batista-Duharte, M. Lastre, B. Romeu, D.L. Portuondo, D. Téllez-Martínez F.A. Manente, O. Pérez, I.Z. Carlos, Antifungal and immunomodulatory activity of a novel cochleate for amphotericin B delivery against Sporothrix schenckii, Int. Immunopharmacol. 40 (2016) 277-287.

[40] A.H. Oliveira, G.G. de Oliveira, F. Carnevale Neto, D.F. Portuondo, A. BatistaDuharte, I.Z. Carlos, Anti-inflammatory activity of Vismia guianensis (Aubl.) Pers. extracts and antifungal activity against Sporothrix schenckii, J. Ethnopharmacol. 195 (2017 Jan 4) 266-274. 